\title{
19. 6-Hydroxydopamine Lesion Prevents Induction of Tyrosine Hydroxylase by Haloperidol in the Rat Substantia Nigra, Pars Reticulata
}

\author{
By Oliver STORK, ${ }^{*}$,***) Michiko KUMAZAKI, **) \\ Hitoo Nishino, ${ }^{* *)}$ and Kunihiko OBATA*) \\ (Communicated by Setsuro EBASHI, M. J. A., June 7, 1994)
}

\begin{abstract}
We investigated the number of tyrosine hydroxylase (TH)-positive neurons in the rat substantia nigra (SN) after unilateral lesion of SN dopamine neurons with intranigral 6-hydroxydopamine (6-OHDA) injection. Non-radioactive in situ hybridization procedure and immunohistochemistry detected much less $(<5 \%)$ TH-positive neurons in the lesioned SN, compared with the contralateral side. Single administration of a dopamine antagonist haloperidol failed to increase $\mathrm{TH}$ labeling on the lesioned side, although it increased that in the contralateral SN pars reticulata ( $\mathrm{SNr}$ ), as in the case of unlesioned animals. These results indicate that 6-OHDA destroyed not only TH-positive $\mathrm{SN}$ neurons but also TH-negative but -inducible $\mathrm{SNr}$ neurons. It is probable that these "TH inducible" SNr neurons are dopaminergic neurons although they usually do not express TH at detectable levels.
\end{abstract}

Key words: Dopamine; substantia nigra; gene expression; in situ hybridization; immunohistochemistry.

Introduction. Nigral dopaminergic neurons release their neurotransmitter, dopamine, both from axon terminals in the striatum and from somata and dendrites in the substantia nigra (SN). ${ }^{6), 9)}$ Most of these neurons are located in the SN pars compacta (SNc), on which most studies have been focussed, but the remaining 10-15\% of tyrosine hydroxylase (TH)-immunoreative neurons are found in the $\mathrm{SN}$ pars reticulata (SNr) with a number similar to that of nondopaminergic nigrostriatal neurons. ${ }^{3), 7)}$ Dopamine has dual actions on striatal neurons via $\mathrm{D}_{1}$ and $\mathrm{D}_{2}$ receptors. ${ }^{4), 13)}$ It inhibits the neighboring dopaminergic neurons in the $\mathrm{SN}^{2,6)}$ and activates some $30-40 \%$ of nondopaminergic neurons in the SNr. ${ }^{14)}$ Moreover, the released dopamine is thought to regulate dopamine synthesis, since acute blockade of dopamine receptors with haloperidol potentiates enzymatic activity of TH. ${ }^{1), 11)}$ This regulation may, at least partly, be achieved by altering TH gene expression, since acute blockade of dopamine $\mathrm{D}_{2}$ receptors with fluphenazine- $\mathrm{N}$ mustard increases cellular levels of $\mathrm{TH}$ mRNA in SNc neurons. ${ }^{19)}$

Recently, we have demonstrated that haloperidol increases the number of $\mathrm{TH}$ immunoreactive and TH cRNA-labeled neurons in the SNr by 70-80\%. ${ }^{16)}$ The origin of these "TH-inducible" neurons could not be determined: it is probable that they are dopaminergic by nature with undetectable amounts of TH mRNA and protein, but it is also possible that nondopaminergic neurons switch their neurotransmitters to dopamine as

*) Laboratory of Neurochemistry, National Institute for Physiological Sciences, Okazaki 444, Japan.

**) Department of Physiology, Nagoya City University Medical School, Nagoya 467, Japan.

***) Present address: Institute for Neurobiology, Swiss Federal Institute of Technology 8093 Zurich, Switzerland. 
occurs in some autonomic neurons. ${ }^{8), 12)}$ In the present communication, this question was addressed by investigating the effect of haloperidol on 6-hydroxydopamine (6-OHDA)lesioned SN. 6-OHDA exerts its selective toxicity on catecholaminergic neurons after being transported by the uptake system of these neurons specific for catecholamines and related substances. ${ }^{17)}$ Therefore, if TH-inducible cells are dopaminergic by nature, 6-OHDA will also destroy them and haloperidol will no longer be able to induce $\mathrm{TH}$ expression.

Methods. Six female Wistar rats (Wistar Shizuoka, 4 weeks old) received single 6-OHDA injections into the left SNc at a dose of $8 \mu \mathrm{g}$ in $4 \mu \mathrm{l}$ saline, delivered over 5 minutes, as described previously. ${ }^{10}$ ) The effect of 6 -OHDA was confirmed one and 2 weeks after the injection by observing turning responses to i.p. administration of methamphetamine (3 mg/kg body weight, Dainippon Pharmaceutical). ${ }^{17)}$ Lesioned animals were kept for another 4 weeks after the second methamphetamine injection in order to avoid any effects of this treatment on TH labeling. Then they received a single i.p. injection of $1 \mathrm{mg} / \mathrm{kg}$ haloperidol (Takeda; $n=2$ ) or saline at equivalent volumes $(n=4)$ and were sacrificed by decapitation after 8 hours. Brains were taken out quickly and frozen with powdered dry ice, and coronal sections of $12 \mu \mathrm{m}$ thickness were prepared and investigated histologically as described previously. ${ }^{16)}$

Results and discussion. Five rats responded with more than 10 turns per minute to methamphetamine both 1 and 2 weeks after 6-OHDA treatment (Table I). Rat s2 turned 3-6 times per minute. This indicates effective lesion of SN dopamine neurons in at least 5 of 6 animals. ${ }^{17)}$

Cresyl violet staining revealed a reduction in the number of neurons in the 6-OHDA-injected SNc (not illustrated). In contrast, changes in the $\mathrm{SNr}$ were not recognized with this method, presumably due to the small percentage of dopaminergic cells in this area. Non-radioactive in situ hybridization histochemistry was performed using an

Table I. Turning responses and nigral $\mathrm{TH}^{+}$cells in 6-OHDA-treated rats. One and 2 weeks after intranigral 6-OHDA injection, methamphetamine was adminstered intra-peritoneally to evaluate the nigral lesion. After another 4 weeks, haloperidol or saline was administered intraperitoneally to rats $\mathrm{h} 1$ and 2 or rats s1-4, respectively, 8 hours before sacrifice. ISH, in situ hybridization and IHC, immunohistochemistry

\begin{tabular}{|c|c|c|c|c|c|c|c|}
\hline \multicolumn{4}{|c|}{$\begin{array}{l}\text { Turning response } \\
\quad \text { (turns/min) }\end{array}$} & \multicolumn{4}{|c|}{$\begin{array}{l}\text { Number of } \mathrm{TH}^{+} \text {cells } \\
\text { (cells/15 sections) }\end{array}$} \\
\hline \multirow[t]{2}{*}{ Animal } & \multirow[b]{2}{*}{ Week 1} & \multirow[b]{2}{*}{ Week 2} & \multirow[t]{2}{*}{ Methods } & \multicolumn{2}{|c|}{ Contralateral } & \multicolumn{2}{|c|}{ Ipsilateral } \\
\hline & & & & $\mathrm{SNc}$ & $\mathrm{SNr}$ & $\mathrm{SNc}$ & $\mathrm{SNr}$ \\
\hline \multirow[t]{2}{*}{$\mathrm{s} 1$} & $10.1 \pm 3.0$ & $11.2 \pm 4.7$ & ISH & 1587 & 209 & $41(2.6 \%)$ & 0 \\
\hline & & & IHC & 1560 & 207 & $36(2.3 \%)$ & 0 \\
\hline \multirow[t]{2}{*}{$\mathrm{s} 2$} & $6.2 \pm 2.7$ & $3.3 \pm 1.8$ & ISH & 1399 & 218 & $64(4.6 \%)$ & 0 \\
\hline & & & IHC & 1420 & 223 & $58(4.1 \%)$ & 0 \\
\hline \multirow[t]{2}{*}{ s3 } & $14.2 \pm 4.3$ & $12.2 \pm 4.1$ & ISH & 1458 & 211 & $53(3.6 \%)$ & 3 \\
\hline & & & IHC & 1483 & 205 & $52(3.5 \%)$ & 2 \\
\hline \multirow[t]{2}{*}{ s4 } & $15.8 \pm 3.4$ & $16.2 \pm 4.4$ & ISH & 1434 & 235 & $34(2.4 \%)$ & 0 \\
\hline & & & IHC & 1410 & 229 & $37(2.6 \%)$ & 0 \\
\hline \multirow[t]{2}{*}{ h1 } & $16.3 \pm 4.8$ & $14.3 \pm 6.4$ & ISH & 1490 & 297 & $30(2.0 \%)$ & 1 \\
\hline & & & IHC & 1510 & 274 & $38(2.5 \%)$ & 1 \\
\hline \multirow[t]{2}{*}{$\mathrm{h} 2$} & $10.2 \pm 4.5$ & $12.2 \pm 3.6$ & ISH & 1478 & 249 & $38(2.6 \%)$ & 0 \\
\hline & & & IHC & 1452 & 241 & $39(2.7 \%)$ & 0 \\
\hline
\end{tabular}




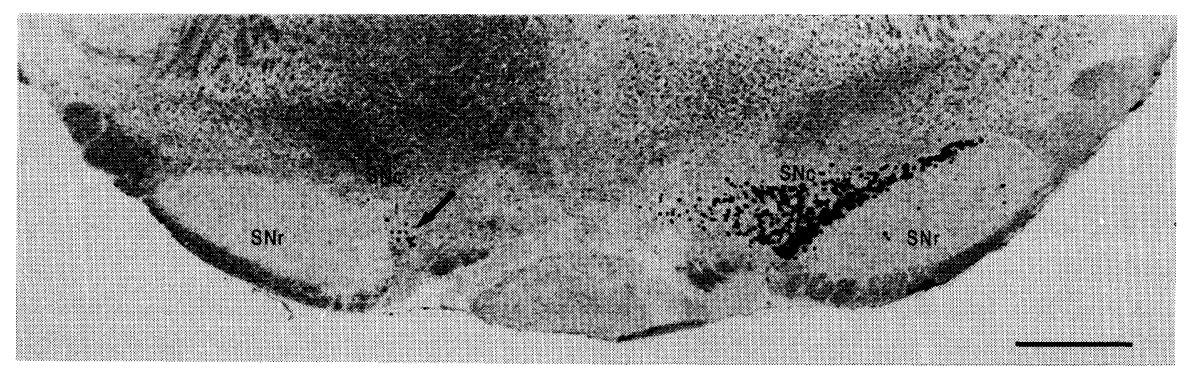

Fig. 1. TH mRNA-expressing cells revealed by in situ hybridization in the rostral SN after haloperidol treatment of an animal lesioned unilaterally by injection of 6-OHDA into the left SNc. On the injected side, no TH mRNA labeling was found in the SNr, whereas a few surviving TH positive cells could be seen in ventromedial aspects of the $\mathrm{SNc}$ (arrow). Contralateral to the injection site, TH positive neurons were labeled in both $\mathrm{SNr}$ and SNc. Bar, $1000 \mu \mathrm{m}$.

antisense riboprobe prepared from a 380-bp Kpn I-EcoR I fragment of the rat TH gene. ${ }^{16)}$ Fluorescence immunohistochemistry was performed with a monoclonal mouse anti-TH antibody (Incstar). ${ }^{16)}$ In situ hybridization (Fig. 1) and immunohistochemistry (not illustrated) generally detected similar numbers of $\mathrm{TH}$-positive $\left(\mathrm{TH}^{+}\right)$cells (Table I) and revealed similar distribution patterns in adjacent sections, as observed previously. ${ }^{16)}$ In all control animals which showed turning response of over 10 turns/min (s1, 3, 4), the number of $\mathrm{TH}^{+}$neurons in the 6-OHDA lesioned SNc was less than $4 \%$ of that of the contralateral SNc (Table I). Only animal s2, which turned less than 10 times/min, showed a slightly higher percentage $(4.6,4.1 \%)$ of surviving $\mathrm{TH}^{+}$neurons in the SNc. This result matches the observation that degeneration of $96 \%$ of SN dopamine neurons is necessary to evoke clear behavioral effects. ${ }^{17)}$ On the other hand, $\mathrm{TH}^{+}$neurons in the $\mathrm{SNr}$ were almost completely removed by 6 -OHDA treatment. Surviving $\mathrm{TH}^{+}$cells were found usually in ventromedial aspects of the anterior $\mathrm{SNc}$ and exceptionally in the $\mathrm{SNr}$ of s3 and $\mathrm{h} 1$. Savasta et al. ${ }^{15)}$ have reported complete disappearance of $\mathrm{TH}$ oligonucleotide labeling after treatment with 6-OHDA, but $15 \%$ of SN neurons with catecholamine fluorescence survive nigral application of a smaller dose $(4.8 \mu \mathrm{g})$ of 6 -OHDA. ${ }^{7}$ This discrepancy may result from differences in the injection site, the dose of 6-OHDA, or detection sensitivity.

Haloperidol treatment did not alter $\mathrm{TH}$ labeling in the $\mathrm{SNc}$ either ipsi- or contralaterally, in accordance with previous observations on the non-lesioned animals. ${ }^{16)}$ It increased the number of $\mathrm{TH}^{+}$cells by $30 \%$ compared with that of saline treatment in the contralateral $\mathrm{SNr}$, but failed to induce $\mathrm{TH}$ labeling in the lesioned $\mathrm{SNr}$ (Table I). This change in the contralateral $\mathrm{SNr}$ differs from that in non-lesioned animals, where haloperidol increases the number of $\mathrm{TH}^{+} \mathrm{SNr}$ neurons by some $80 \%$. It is interesting to further investigate the reason for this discrepancy. However, the disappearance of $\mathrm{TH}^{+}$ neurons from lesioned $\mathrm{SNr}$ and the failure to induce them by haloperidol suggest that "TH inducible" SNr neurons are removed by 6-OHDA treatment, together with constitutively TH-expressing SN neurons. It is considered that "Tï inducible" $\mathrm{SNr}$ neurons are able to take up and metabolize dopamine and, therefore, are dopaminergic, although they usually do not contain detectable amounts of TH protein or mRNA.

More than $95 \%$ of nigrostriatal neurons in the entire SN show glyoxylic acid-induced catecholamine fluorescence, ${ }^{7), 18)}$ but only about $85 \%$ appear to be TH-immunoreactive. ${ }^{5)}$ Therefore, some $10 \%$ of nigrostriatal neurons would usually contain dopamine, but appear $\mathrm{TH}^{-}$by immunohistochemistry and probably in situ hybridization. This population might include "TH inducible" neurons in the SNr. 
Acknowledgments. This work was supported in part by grants from the Ministry of Education, Science and Culture, Japan, and the Uehara Memorial Foundation. O. S. was supported by the Japanese German Center Berlin (1992) and Kanehara Memorial Foundation (1993).

\section{References}

1) Argiolas, A. et al. (1982): J. Neurochem., 38, 75-79.

2) Bjorklund, A., and Lindvall, O. (1975): Brain Res., 83, 531-537.

3) Faull, R. L. M., and Mehler, W. R. (1978): Neuroscience, 3, 989-1002.

4) Gerfen, C. R. (1992): Trends Neurosci., 15, 133-139.

5) Gerfen, C. R. et al. (1987): J. Neurochem., 7, 3915-3934.

6) Groves, P. M. et al. (1975): Science, 190, 522-529.

7) Guynet, P. G., and Crane, J. K. (1981): Brain Res., 213, 219-305.

8) Le Douarin, N. M. (1980): Nature, 286, 663-669.

9) Nieoullon, A. et al. (1977): ibid., 266, 375-377.

10) Nishino, H. et al. (1990): Brain Res., 534, 83-93.

11) Nissbrandt, H. et al. (1989): J. Neurochem., 52, 1170-1182.

12) Patterson, P. H. (1978): Ann. Rev. Neurosci., 1, 1-17.

13) Robertson, H. A. (1992): Trends Neurosci, 15, 201-205.

14) Ruffieux, A., and Schultz, W. (1980): Nature, 285, 240-241.

15) Savasta, M. et al. (1989): Neuroscience, 29, 363-369.

16) Stork, O. et al. (1994): Brain Res., 633, 213-222.

17) Ungerstedt, U., and Arbuthnott, G. W. (1970): ibid., 24, 485-493.

18) van der Kooy, D. et al. (1981): Neuroscience, 6, 345-357.

19) Weiss-Wunder, L. T., and Chesselei, M. -F. (1992): ibid., 49, 297-305. 